\title{
Pharma Success in Product Development-Does Biotechnology Change the Paradigm in Product Development and Attrition
}

\author{
Ronald P. Evens ${ }^{1,2,3,4}$
}

Received 14 September 2015; accepted 29 September 2015; published online 16 October 2015

\begin{abstract}
The biotechnology segment of the overall biopharma industry has existed for only about 40-45 years, as a driver of new product development. This driving force was initiated with the FDA approval of recombinant human insulin in 1982, originating from the Genentech company. The pharma industry in the early years of 1970s and 1980s engaged with biotechnology companies only to a small extent with their in-licensing of a few recombinant molecules, led by Roche, Eli Lilly, and Johnson and Johnson. However, subsequently and dramatically over the last 25 years, biotechnology has become a primary driver of product and technology innovation and has become a cornerstone in new product development by all biopharma companies. This review demonstrates these evolutionary changes regarding approved products, product pipelines, novelty of the products, FDA approval rates, product sales, financial R\&D investments in biotechnology, partnerships, mergers and acquisitions, and patent issues. We now have about 300 biotechnology products approved in USA covering 16 medical disciplines and about 250 indications, with the engagement of 25 pharma companies, along with their biotechnology company innovators and partners. The biotechnology pipeline involves over 1000 molecules in clinical trials, including over 300 molecules associated with the top 10 pharma companies. Product approval rates by the FDA for biotechnology products are over double the rate for drugs. Yes, the R\&D paradigm has changed with biotechnology now as one of the major focuses for new product development with novel molecules by the whole biopharma industry.
\end{abstract}

KEY WORDS: attrition; biotechnology; health care advances; product approvals; science innovation.

The troublesome and complicating hallmarks of product development in the biopharma industry are a very high and well-known failure rate, the very high and rising costs on $\mathrm{R} \& \mathrm{D}$ investments required, the substantially growing data requirements in regulatory filings, and the extended timelines for research and development for new products, often $8-10$ years. As molecules progress through the phases of research, attrition rates as high as $90 \%$ exist for the clinical trials stages collectively, even after the elimination of molecules during discovery, laboratory, and preclinical research stages. Costs of drug development have recently been published with an ever increasing total, that is, estimates of $\$ 2.59$ billion in

Invited manuscript from the annual AAPS National Biotechnology Conference, June 9, 2015, in San Francisco, CA. "Characteristics of Successful Drug Development Programs - What can we do to Improve Attrition"

${ }^{1}$ Center for the Study of Drug Development, Tufts University School of Medicine, Boston, Massachusetts, USA.

${ }^{2}$ Thomas J. Long School of Pharmacy, University of the Pacific, Stockton, California, USA.

${ }^{3}$ M.A.P.S. 4 Biotec, Inc., Napa, California, USA.

${ }^{4}$ To whom correspondence should be addressed. (e-mail: medaff4biopharma@aol.com)
2014 , versus $\$ 1.04$ billion in 1990s and \$413 million in 1980s (1). Clinical data requirements have grown dramatically with more patients, more disease endpoints, more inclusion criteria, and many more tests, e.g., 167 procedures per protocol in 2009 versus 96 in 1999 (2,3). Amendments to protocols after clinical trials were initiated are yet further data and process problems, e.g., amendments were needed in $60 \%$ of protocols and 2.3 amendments per protocol, requiring 60 days to resolve (4). The timeframe has grown for the clinical phases of research to be about 8 years, even with FDA review times being reduced over last two decades, now averaging about 1 year for standard reviews $(5,6)$. The FDA role in facilitating product development can be observed by the manifold process improvements over the last 20 years, e.g., the dramatic reduction in their review times, predicated on manifold new legislation and regulations, such as Prescription Drug User Fee Act (PDUFA), accelerated reviews, priority reviews, sponsor-FDA in process meetings, orphan drug designations, special protocol assistance, special review vouchers, and breakthrough therapy designations (7).

The question addressed in this manuscript is what is the impact of biotechnology on the success of product development in the biopharma industry? Biotechnology in the subsequent discussion encompasses the following biotech product types: recombinant 
proteins (hormones, enzymes, growth factors, coagulation factors, interferons, interleukins), monoclonal antibodies and derivatives, peptides (recombinant and synthetic with molecular engineering), vaccines (recombinant and molecularly engineered), fusion proteins, pegylated peptides and proteins, liposomal molecules, RNA inhibitory/antisense therapies, gene therapies, and cell therapies. The data and discussion herein were presented at the American Association of Pharmaceutical Scientists, National Biotechnology Conference, in San Francisco, CA, on June 9, 2015.

The success of biotechnology in the biopharma industry can be well documented now by the extensive number and the broad scope of scientific advances for the currently approved biotech products, the clinical impact of biotechnology products in advancing health care, the sizable sales of biotech products including many blockbusters ( $\$ 1$ billion in sales in 1 year), extensive financial investment in biotechnology companies, uniform engagement of all pharma companies in biotechnology, the consistently higher success rates annually for new biotech product approvals, and the significant research pipelines for biotechnology molecules. These favorable impacts of biotechnology on new product approvals has evolved only in the past 32 years since the approval of the first product considered to be biotech in origin, recombinant human insulin in 1982, up to today, 2015. Evolution of the biotechnology industry (both science and business) involved simultaneously, and in an integrated nature, scientific advances with novel technologies, generally favorable government regulations, novel business practices, and the new products expanding and advancing patient care, all of which were recently reviewed in Health Affairs in February 2015 (8).

FDA approvals of biotech products now impressively number about 300 products occurring over 35 years: antibodies (44), cell/tissues therapies (18), coagulation proteins (19), enzymes (24), fusion proteins (21), genetic therapies (3), growth factors (16), hormones (57), interferons (12), interleukins (4), liposomes (10), peptides (57), vaccines (18), and others (15) (9). The rate of biotech product approvals in USA has grown to be about 12 products per year for the last 15 years, as demonstrated by 5 year windows in Fig. 1 (9). Plus over 130 added indications are approved by FDA as well over the same timeframes. The breadth of the health care impact of biotech products is equally impressive, based on number of indications in 16 medical disciplines listed: cardiology -14 , dermatology -17 , endocrinology -24 , gastroenterology -7 , gynecology-12, hematology-11, infectious disease - 26, nephrology - 3, neurology - 11, oncology - 59, ophthalmology - 10, pediatrics - 50+, pulmonary - 4, rheumatology -13 , surgery -4 , urology -5 , and others - $23(8,10)$. Many indications revolutionized the care of patients with novel mechanisms of actions to substantially arrest disease progression or even create cures for the first time in many diseases, e.g., interferons in multiple sclerosis; monoclonal antibodies in breast cancer, respiratory syncytial virus infection, and psoriasis; fusion proteins for macular degeneration and rheumatoid arthritis; enzymes for Gaucher's disease and Fabry's disease; and proteins for anemia and childhood growth deficits. Of the new molecular entities and new biologic entities approved by FDA, biotech products now have comprised about one third of them annually for the last 15 years (Fig. 2) (11), which was also suggested in a related analysis by HBM partners, stating that $53 \%$ of new medicinal entities (NMEs) emanated from in-house sources versus $47 \%$ from in-licensing and mergers and acquisitions (12). The novelty of biotech products has been stated to exceed significantly that of drugs approved by the FDA over the 29 years from 1986 to 2014, comparing NMEs (drugs) to new biologic entities (NBEs), adapted from an analysis by FDA management published in Nature Reviews Drug Discovery in 2015 (Fig. 3) (13). For example, first-inclass designations were $53 \%$ for biotech products versus $24 \%$ for drugs.

The commercial success of biotech products is another key parameter demonstrating biotech's favorable impact on product development. In 2002, biotech product sales were under 40 billion USD, only about $8 \%$ of all drug sales, and increased in 2007 to about 90 billion USD, about $13 \%$ of all sales, and then dramatically up to about 165 billion USD in $2012,19 \%$ of total drug sales (14). In 2014, biotech sales were about 195 billion USD, $18 \%$ of drug and product sales worldwide (15). Furthermore, biotech products comprise seven of the top 10 drugs, based on 2014 worldwide sales, that is, Humira (Biotech)-12.9 billion USD, Sovaldi (Drug)—10.0 billion, Remicade (B) -9.9 billion, Enbrel (B) - 8.9 billion, Rituxan (B) - 8.6 billion, Lantus (B) -8.2 billion, Advair (D) -6.9 billion, Avastin (B) -7.1 billion, Herceptin (B) -6.8 billion, and Januvia (D) -6.0 billion (15). In addition, 52 biotech products (plus 3 biologic blood derivatives) were blockbusters versus 67 drugs in 2014 (15). A blockbuster product is defined as a product with $\$ 1$ billion in sales in 1 year. Pharma companies commonly market a very large number of the biotech products: the top 10 pharma companies market over 160 biotech products. The top 5 companies in 2014 were Roche- 30.1

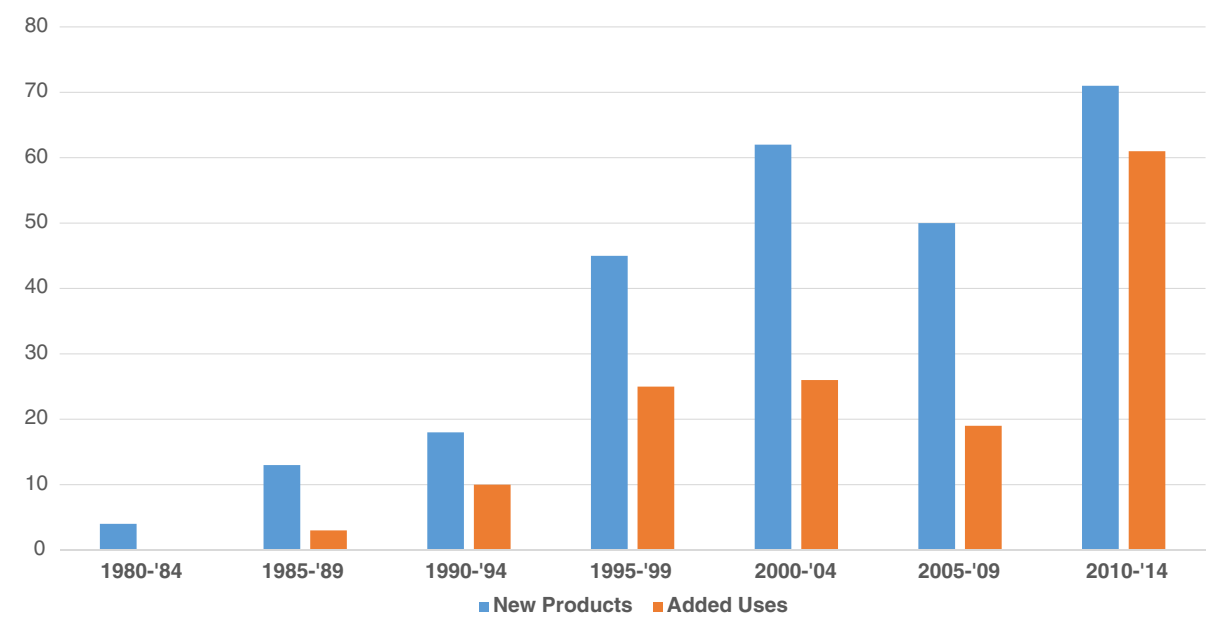

Fig. 1. Biotech approvals with FDA—new products and added uses, 1980 to 2014 


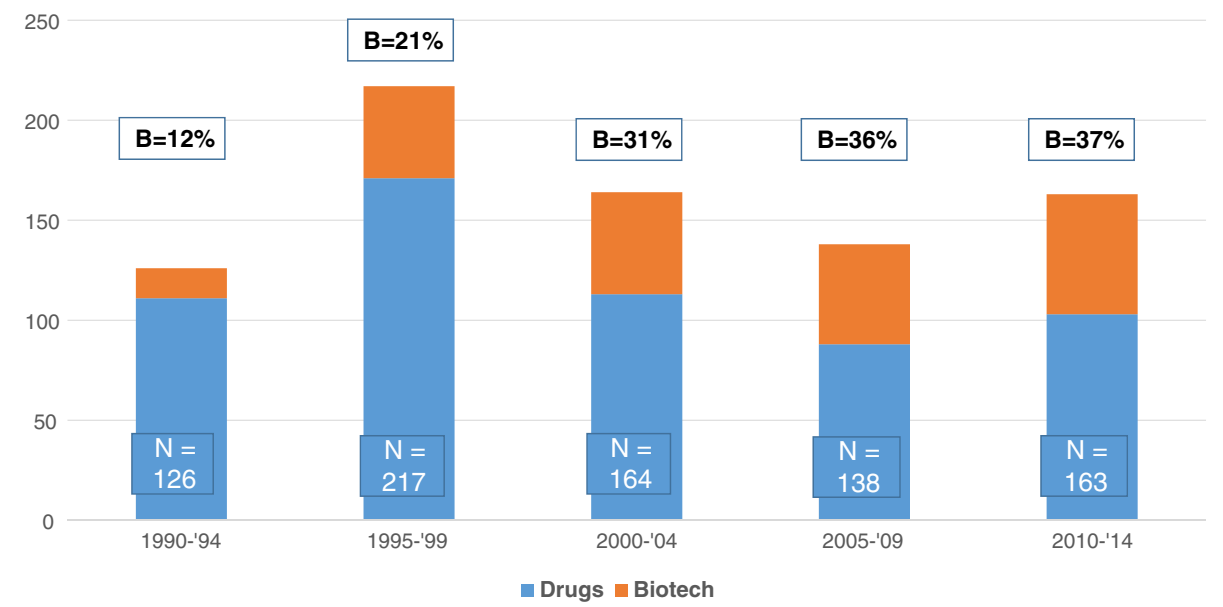

Fig. 2. FDA NME and NBE approvals, 1990 to 2014

billion USD in biotech sales (21 bio-products), Sanofi-13.9 billion USD (23 bio-products), Novo Nordisk-14.2 billion USD (11 bio-products), AbbVie-13.9 billion USD (7 bio-products), and Pfizer-13.3 billion USD (14 bio-products) (8). Because of the novelty of the biotech molecules and their substantial impact on disease progression, biotech products have been generally well received by payers in health care systems with routine formulary approvals, even with the premium pricing carried by these products. However, over 10 new products to treat cancer in the last few years were priced at over 100,000 USD per year per patient, along with a continuing stream of many new orphan drugs costing from $\$ 150,000$ to $\$ 500,000$ per year, hepatitis drugs at $\$ 80,000$ per year, and others. Hence, especially in 2015 , the payers are strongly pushing back on these prohibitively high prices for new biotech products demanding heavy price discount demands and formulary restrictions.

Patent issues are yet another major advantage of biotech products versus drugs. A drug often comes to market with less than 5 years of patent life and exclusivity having been discovered and patented in its early research stages. A biotech product will carry multiple patents for the molecule and possibly several steps in their complex and sophisticated manufacturing processes, such as the bacterial vectors and host cells in recombinant DNA molecule manufacturing, in addition to the molecule. Eight to 10 years or more has been a common patent life for biotech products. Also, the new law in 2010, Patient Protection and
Affordable Care Act, contained biotech provisions including a minimum patent life post approval of 12 years.

The success rate of regulatory approvals for biotech products far exceeds the drug approval rates, that is, by at least twofold. DiMasi studied product approvals by the US FDA for the 50 largest pharmaceutical companies over 1993 to 2009, covering 1738 molecules (16). Although the overall FDA product approval rate was $16 \%$, the approval rate from phase 1 clinical trial initiation to approval was $32 \%$ for large molecules versus $13 \%$ for small molecules (drugs). Philippidis presented approval data for FDA drugs covering 2006 to 2010 for 13 pharma companies (Abbott, AstraZeneca, Bayer, Boehringer-Ingelheim, BristolMyers Squibb, Eli Lilly, GlaxoSmithKline, Johnson and Johnson, Merck, Novartis, Pfizer, Roche, Sanofi) (17). Again, large molecules more than doubled the success rates for product approvals versus small molecules, $25 \%$ versus $10 \%$. KMR consulting group in their pharmaceutical benchmarking forum presented data for 4275 drugs and 7300 indications from their BioMedTracker system; biologic approval rate was $26 \%$ versus new molecular entities (drugs) of 14\% (18). Furthermore, Hay used a sample of 825 companies with 4451 drugs or biologicals (19). He examined "likely-hood-of-approval" (LOA) for phase 1 clinical trials up to FDA approvals: drugs achieved a LOA of only $8 \%$ versus biologics of $15 \%$, including $13 \%$ for proteins, $14 \%$ for monoclonal antibodies, and $15 \%$ for vaccines (19). Orphan drugs had a success rate of product approval of $33 \%$,

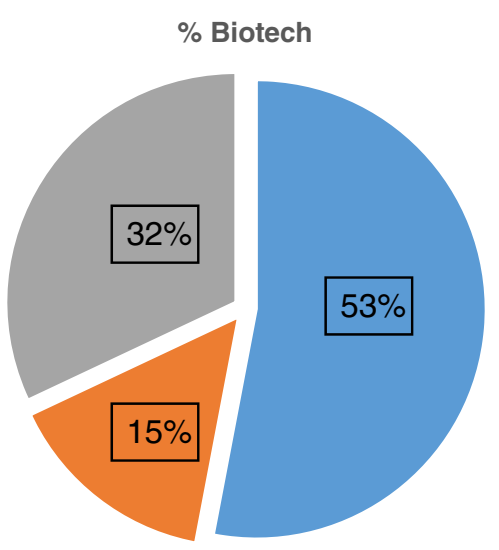

1st-In-Class Advance-In-Class Add-On

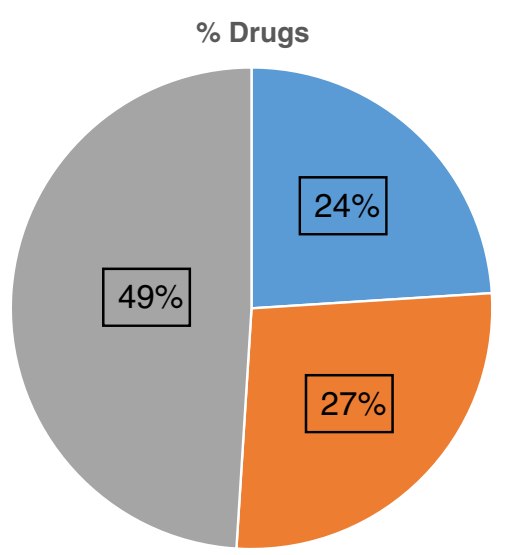

1st-In-Class Advance-In-Class Add-On

Fig. 3. Product "innovation"-NBEs and NMEs-1986 to 2014 
and if a sponsor for a product had utilized a special protocol assessment from the FDA, a $45 \%$ success rate was achieved. Failure to achieve regulatory approval was attributed to efficacy issues, $48 \%$ of the time, safety $31 \%$, commercial issues $8 \%$, and unknown $13 \%$. Table I summarizes these four data sets.

Biotech products in clinical trials have reached over 900 according to a PhRMA 2012 report (20). About 325 molecules are in phase 3 clinical trials as of August 2015, of which pharma companies are engaged in 141 molecules (21). The involvement of pharma companies has grown substantially from $22 \%$ of the biotech molecules in clinical trials in 2001 to $47.5 \%$, either alone or in collaboration with a biotech company in 2012 (22). The top 10 companies with significant biotech clinical product pipelines in 2012 were Roche-51, GlaxoSmithKline-50, Novartis - 44, Sanofi-40, Eli Lilly-36, AstraZeneca-32, Pfizer-32, BristolMyers Squibb-21, Johnson and Johnson-19, and Merck-17 (8). Monoclonal antibodies ranked first in type of molecules in clinical trials with pharma companies in 2012 at 248, followed by vaccines at 77 and proteins at 34 .

Financial investment is very strong for biotechnology companies in partnerships from pharma companies, in addition to heavy commitments in initial public offerings and substantial venture capital investments. Total biotech financing according to Ernst and Young biotech annual reports was 74.2 billion USD in 2012, 79.7 billion in 2013 and up to 107.9 billion in 2014 (23-26). Partnership investments from other companies were the largest source of financing for biotech companies, that is, 38 billion USD $(51 \%$ of total financing) in 2013, 43 billion USD (54\%) in 2013, and 53 billion (49\%) in 2014. Basically, the money for new research investments has followed the advances in science, well represented in biotech research and development. Furthermore, pharma companies have so highly valued the research pipelines and product opportunities in biotechnology that 31 pharma companies have acquired by purchase 132 biotech companies over 1998 to 2012 at an overall cost of \$318 billion (14). The high science valuation and strong business opportunities, based on these acquisitions of biotech companies, accelerated over time: 15 deals for \$26 billion in 1998-2002, 43 deals for $\$ 78$ billion in 2003-2007, and 74 deals for $\$ 215$ billion in 2008-2012 (14). Over this 15-year period, all the top 10 biotech companies were acquired except for Amgen, Gilead, and Regeneron.

A further current example of biotech innovation at the cutting edge of science and novel patient care, along with the need to move expeditiously with research investments, is the explosion of work and investment in the immuno-oncology $(\mathrm{I} / \mathrm{O})$ arena in just the last 3 years, 2013-2015 (27). Although only three immune-oncology products have established efficacy and FDA approval by June 2015, ipilimumab and nivolumab from Bristol-Myers Squibb and pembrolizumab from Merck, and exciting patient responses (cures) were observed with the work at University of Pennsylvania in leukemia, much research and massive financial commitments already have been made in immuno-oncology. The promise for exceptional advances in science and cancer care and substantial financial opportunities are the drivers. Many disease targets already have been identified, e.g., CLTA4, LAG3, OXO4, PD1, PDL1, and TIM3 (28). Business press reports are replete with all the recent developments and investments in immuno-oncology, some of which are summarized in the subsequent comments. Biotech companies focused on CAR-T (Chimeric Antigen Receptor for T lymphocytes) treatment and related therapies, enhancing immune system attack on cancer, have gone public with exceptionally large IPOs, over an astronomical $\$ 1.48$ billion in a 1-year period (2014/2015) with just eight companies, Juno $\$ 300$ billion, Kite $\$ 128$ billion, Bluebird $\$ 166$ billion, Bellicum $\$ 140$ billion, Adaptimmune $\$ 191$ billion, Cellectis \$228 billion, Aduro \$119 billion, and NantWorks \$207 billion (27). Alliances between biopharma companies and universities and biotech companies have exceeded $\$ 8$ billion by mid-2015 in upfront and potential milestone payments, e.g., Novartis - University of Pennsylvania; Celgene-Juno and Bluebird; Pfizer-Cellectis; Roche-NewLink and Clovis; Johnson and Johnson-Aduro, Alligator Biosciences, and Posiedan Therapeutics; Amgen-Kite; Merck and Immune Design; and AstraZeneca and Immunocor. Company acquisitions have already occurred in 2015 to access novel technologies in immuno-oncology as well, e.g., Juno with Stage Cell and X-Body, Bristol-Myers Squibb with Flexus, and Novartis and CoStim. Vaccines, as potential immuno-oncology (I/O) enhancers in combination with $\mathrm{I} / \mathrm{O}$ products, have seen a rejuvenation of research engagement in clinical trials for many vaccines, for example, by Amgen, Aduro, Biovest, CellDex, Galena, NewLink, Prima, and others.

\section{CONCLUSION}

Biotech dramatically has improved the success of product development in the pharmaceutical industry and has become a cornerstone in new and novel product development. The biotech focus that has existed for the past 30 years and still remains is "innovation" in medical science and patient care. The breadth and novelty of new products has been impressive. Patents for biotech products are stronger and longer. Provider acceptance for biotech products has engaged primarily specialists and exists at a higher level versus drugs. Product pipelines for biotech across the whole pharma industry are robust. FDA approval rates for biotech products exceed drugs. Biotech product sales now lead sales in the biopharma industry. Investments in business and research and development are very strong for alliances, venture capital, and IPOs. Partnerships between pharma and biotech companies are yet another success factor in novel and new product development.

Table I. Success Rates in FDA Product Approvals

\begin{tabular}{lllcc}
\hline Research group & Dates & Number of molecules & Success of small molecules (\%) & Success of large molecules (\%) \\
\hline DiMasi et al. & $1998-2009$ & 1738 & 13 & 32 \\
Philippidis & $2006-2010$ & $(13$ companies) & 10 & 25 \\
Hay et al. & $2003-2011$ & 4451 & 8 & 15 \\
KMR group & $2003-2010$ & 4275 & 14 & 26 \\
\hline
\end{tabular}




\section{REFERENCES}

1. DiMasi JA, Grabowski HG, Hansen RW. Costs of developing a new drug. Tufts Center for the Study of Drug Development Briefing. Innovation in the pharmaceutical industry: new estimates of R\&D costs. 2014.

2. Getz K. Rising protocol complexity, execution varies widely by phase and TA. Tufts Center for the Study of Drug Development. Kaitin KI (ed). Impact Report 2010;12(3):1-4.

3. Getz K. Growing protocol design complexity stresses investigators, volunteers. Tufts Center for the Study of Drug Development. Kaitin KI (ed). Impact Report 2008;10(1):1-4.

4. Getz K. Nearly $60 \%$ of all protocols require amendments. Onethird are avoidable. Tufts Center for the Study of Drug Development, Kaitin KI (ed). Impact Report 2011;13(5):1-4.

5. Kaitin KI. While total approvals decline, U. S. is preferred market for first launch. Tufts Center for the Study of Drug Development. Kaitin KI (ed). Impact Report 2008;10(6):1-4.

6. Reichert J. Biopharmaceutical product approvals in the U.S. rose dramatically in 2000s. Tufts Center for the Study of Drug Development. (Kaitin KI (ed). Impact Report 2011;13(3):1-4.

7. Guidance for Industry. Expedited programs for serious conditions-drug and biologics. HHS, FDA, CDER, CBER. May 2014. Silver Springs, MD.

8. Evens R, Kaitin K. The evolution of biotechnology and its impact on health care. Health Aff. 2015;34(2):210-9.

9. Evens REP. Product data-on-file, Tufts University Center for the Study of Drug Development. August 2015.

10. Evens RP. Medical usage data-on-file, Tufts University Center for the Study of Drug Development. August 2015.

11. Evens RP. Product approval data-on-file from FDA Databases, Tufts Center for the Study of Drug Development. June 2015.

12. HBM New Drug Approval Report. Trends in New Drug Approvals by US FDA (2003-2013). Darmstadt, Germany. Feb. 2014 www.hbmpartners.com/en/indystryreports/new-drugapproval-report.php

13. Miller KL, Lanthier M. Innovation in biologic new molecular entities: 1986-2014. Nat Rev Drug Discov. 2015;14(2):83.

14. Evens RP, Kaitin KI. The biotechnology innovation machine: a source of intelligent biopharmaceuticals for the pharma industry-mapping biotechnology's success. Clin Pharmcol Therap. 2014;95(5):528-32.
15. Evens RP. Product and sales data-on-file from 2014/2015 company annual reports at Tufts Center for the Study of Drug Development, June 2015

16. DiMasi JA, Feldman L, Seckler A, Wilson A. Trends in risks associated with new drug development: success rates for investigational drugs. Clin Pharmacol Therap. 2010;87(3): 272-7.

17. Philippidis A. Large molecules continue to gain favor. Gen Eng News. 2012;32(10):10-1.

18. KMR Group. Pharmaceutical Benchmarking Forum. Probability of success by molecule size: large vs small molecules. Chicago: KMR Group; 2012.

19. Hay M, Thomas DW, Craighead JL, Economides C, Rosenthal J. Clinical development success rates for investigational drugs. Nat Biotechnol. 2014;32(1):40-51.

20. Medicines in development. Biologics. 2013 Report. Pharmaceutical Research and Manufacturers of America. Washington, DC; 2013.

21. Evens RP. Products in phase 3 trials. Data-on-file, Tufts Center for the Study of Drug Development. 2015.

22. Evens RP. Biotech products in big pharma clinical pipelines have grown dramatically. Tufts University Tufts CSDD, Kaitin KI (ed), Impact Report 2013;15(6):1-4.

23. Licking E, Jaggi G. Beyond Borders. Biotechnology industry report 2015. In: Giovannetti GT editor. The year in review. Reaching new heights. Biotechnology annual report 2015. San Francisco: Ernst \& Young; p. 1-73.

24. Licking E, Jaggi G. Beyond borders. Biotechnology industry report 2015. In: Giovannetti GT editor. The year in review. Unlocking value. Biotechnology annual report 2014. San Francisco: Ernst \& Young; p. 1-103.

25. Jaggi G. Beyond Borders. Biotechnology industry report 2015. In: Giovannetti GT editor. The year in review. Matters of evidence. Biotechnology annual report 2015. San Francisco: Ernst \& Young; p 1-85.

26. Urquhart L, Hiss PA editors. EvaluatePharma World Preview 2015. Outlook 2020. 8th ed. London; 2015. p 1-69.

27. Evens RP. Product and company data-on-file, Tufts Center for the Study of Drug Development. 2015.

28. Mahoney KM, Rennert PD, Freeman GJ. Combination cancer immunotherapy and new immune-modulatory targets. Nat Rev Drug Discov. 2015;14(8):561-84. 